\title{
A Revolução Mexicana nos livros didáticos de História do PNLD 2018
}

\begin{abstract}
Maria Luiza Pérola Dantas Barros ${ }^{1}$
Resumo: Este artigo tem por objetivo entender como a Revolução Mexicana, iniciada em 1910, aparece nos livros didáticos de História aprovados pelo Programa Nacional do Livro Didático (PNLD) 2018 e destinados aos alunos e professores do terceiro ano do ensino médio ${ }^{2}$ das escolas públicas brasileiras. Para tanto, inicialmente buscou-se compreender como os autores trabalharam a temática em suas respectivas obras (quais fatos elencaram e a partir de quais abordagens, por exemplo). Em seguida, lançou-se um olhar acerca da maneira como as fotografias, entendidas aqui como uma representação do real (KOSSOY, 2009), relacionadas à revolução são trabalhadas nas respectivas obras: se como fontes ${ }^{3}$ no ofício de narrar os fatos históricos, como era a exigência do Edital $2018^{4}$, ou como ilustração.
\end{abstract}

Palavras-chave: Revolução Mexicana. Fotografias. PNLD 2018.

\section{The Mexican Revolution in the PNLD History textbooks 2018}

Abstract: This article aims at understanding how the Mexican Revolution, started in 1910, appears in History textbooks approved by the National Textbook Program (PNLD) 2018 aimed at students and teachers in the third year of high school of Brazilian public schools. To this end, we initially sought to understand how the authors worked on the theme in their respective works (which facts they listed and from which approaches, for example). Then, a look was taken at how the photographs, understood here as a representation of the real (KOSSOY, 2009), related to the revolution are approached on in the respective works: whether as sources in the craft of narrating historical facts, as it was the requirement of the 2018 Notice, or as an illustration.

Keywords: Mexican Revolution. Photographs. PNLD 2018.

Artigo recebido em: 01/02/2020

Artigo aprovado para publicação em: 28/03/2020

\footnotetext{
${ }^{1}$ Mestra em Educação (PPGED/UFS). Graduada em História (DHI/UFS). Integrante do Grupo de Estudos do Tempo Presente (GET/UFS/CNPq). E-mail: malupedanbar@gmail.com.

${ }^{2}$ Considerando o marco temporal do processo revolucionário, já que os livros destinados ao terceiro ano do ensino médio abrangem do final do século XIX/início do século XX até os dias atuais.

${ }^{3}$ Entendidas aqui como sinônimo de documento, no que se refere aos vestígios deixados pelos seres humanos ao longo do tempo, que acabam por fornecer indícios do passado, foram apresentadas no Edital 2018 como imprescindíveis ao ofício de historiar, devendo ser diversas e bem trabalhadas, possibilitando diferentes pontos de vista de um mesmo fato histórico, dentro do livro didático.

${ }^{4}$ BRASIL. MEC. Edital de Convocação 4/2015-CGPLI. Processo de Inscrição e Avaliação de Obras Didáticas para o Programa Nacional do Livro Didático - PNLD 2018. Brasília: MEC, 2015.
} 


\title{
A Revolução Mexicana: um olhar panorâmico
}

No domingo, 20 de novembro de 1910, o povo mexicano poderia ler na primeira página do jornal El Diário a seguinte manchete: "As autoridades de toda la Rapublica

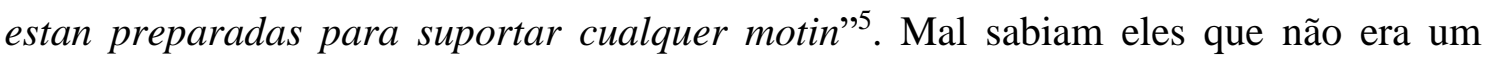
simples motim, mas uma revolução ${ }^{6}$ que se projetava naquela sociedade.

Não há um consenso entre os estudiosos da temática quanto ao recorte temporal da Revolução Mexicana, como deixam claro Ana Paula Cantarelli e Erivelton Franco de Lima, em trabalho intitulado Em busca de uma ideologia para a Revolução Mexicana (2013), ao afirmarem que:

\begin{abstract}
Alguns apontam o ano de 1917, com a proclamação da Constituição do México, como o final da revolução, outros defendem que o término ocorreu somente em 1920 com a presidência de Adolfo De la Huerta e outros elegem o ano de 1924, quando Plutarco Elías Calles assumiu o poder, como o ano derradeiro da revolução. Já o historiador inglês Alan Knight, da Universidade de Oxford, considera que o real término ocorreu apenas nos anos de 1940. A partir dessas diferentes datas, o que fica claro é que o processo revolucionário ainda se estendeu por algum tempo após o término dos conflitos armados (CANTARELLI; LIMA, 2013, p. 90).
\end{abstract}

O autor Carlos Alberto Sampaio Barbosa, na introdução do seu livro A fotografia a serviço de Clio: uma interpretação da história visual da Revolução Mexicana (19101940) (2006), menciona, por exemplo, a periodização de 1910 até o governo de Lázaro Cárdenas (1934-1940), por este ter sido responsável pelo atendimento de diversas demandas sociais surgidas durante a luta armada, dando um caráter social para a revolução $(2009$, p. 15).

Pode-se afirmar que os eventos processados naquele momento atingiram uma importância na sociedade mexicana e para além dela, podendo ser considerados marcos

\footnotetext{
${ }^{5}$ El Diario, 20 de novembro de 1910, p. 2.

${ }^{6} \mathrm{O}$ termo é entendido aqui como um evento ocasionador de uma ruptura na História, com o intuito de mudar (o homem, o mundo conhecido, por exemplo) para melhor.
} 
da primeira revolução do século XX. Da mesma forma, a última das revoluções burguesas e a primeira das revoluções proletárias, tão importante que muitos consideram que nada teria sido o mesmo na América Latina (TOSI, 2016, p.144) após tais eventos, já que aquela seria a primeira revolta popular de âmbito e alcance nacional do continente (STREICH, 2017, p.116 e 117), tornando-se referência para outras lutas na América. Por tudo isso, tal revolução seria considerada por alguns estudiosos como um marco para o início da Idade Contemporânea na América Latina, mesmo que paradoxalmente seja pouco conhecida na região marcada por estudos fixados no eurocentrismo (RAMPINELLI, 2011, p.90).

Um olhar para o México pré-revolucionário possibilita perceber as contradições internas existentes, que tornaram o terreno fértil para um processo revolucionário, como afirma Loudes Kaminski Alves, em Representações literárias da Revolução Mexicana na narrativa de Juan Rulfo (2017), a desigualdade e a injustiça social seriam alguns dos fatores para a Revolução Mexicana, e nas décadas que antecederam 1910, profundas rupturas marcaram a sociedade, acarretando problemas econômicos, políticos e sociais, tendo de um lado uma elite favorecida pela política governamental, e do outro um número cada vez maior de pessoas expropriadas de suas terras (p. 137 e 138). Como afirma Waldir José Rampinelli, em A Revolução Mexicana: seu alcance regional, precursores, a luta de classes e a relação com os povos originários (2011):

Essas expropriações de territórios imensos, que assumiram formas de uma verdadeira guerra colonial, aconteceram também de maneira sistemática contra as terras comunais dos povos indígenas nas demais regiões do país - na verdade, guerras das fazendas contra os povoados, apoiadas ou pelo Exército Federal ou pelas Guardas Rurais (RAMPINELLI, 2011, p.92).

O governo de Porfírio Díaz (1865-1911), apontado como aquele que desenvolveu e modernizou o México, integrando-o ao mercado mundial, continha marcas autoritárias que acabaram acarretando sofrimento às camadas populares e expropriação das terras dos pequenos proprietários em benefício dos grandes latifúndios. Como afirma José Gaspar Bisco Júnior, em México Insurgente: Da Revolução Mexicana ao surgimento do EZLN (2003): 
O problema agrário é tido como o principal problema do México e somasse a isso a necessidade de criação ou reformulação de uma constituição que de direitos e igualdade aos povos indígenas, respeitando suas particularidades e dando condições para que este povo, que também é mexicano, consiga ter condições de preservar sua cultura (BISCO JÚNIOR, 2003, p. 10).

Em seu trabalho, Bisco Júnior afirma que tanto a questão agrária quanto os conflitos de classes resultantes da luta pelo controle de terras estariam presentes na história mexicana desde o período colonial, mas que em 1910, menos de 5\% das terras estariam nas mãos dos pequenos proprietários.

De acordo com o autor, não só os pequenos proprietários estavam insatisfeitos. Quando Porfírio Díaz é reeleito em 1884, os Estados Unidos atravessavam uma crise econômica que acarretou prejuízos à economia mexicana. Isso somado aos problemas climáticos (como secas, por exemplo) fazia com que a agricultura e a pecuária tivessem um dano de $50 \%$ na produção. Tal cenário ainda era acrescido das ideias que circulavam naquela sociedade, isso levando em consideração que uma revolução também é feita no campo das ideias.

Autores como Cantarelli e Lima destacam que o processo revolucionário mexicano fora pontuado por três ideólogos: Andrés Molina Enriquéz (1868- 1940), defendendo a elaboração de um projeto de política nacional que buscasse solucionar os problemas econômicos e sociais do país ao mesmo tempo em que fosse capaz de despertar um espírito nacional forte; Ricardo Flores Magón (1873-1922), compreendendo os problemas das massas a partir de uma concepção de justiça na qual o valor da liberdade individual fosse o verdadeiro centro de ação, e Francisco Madero (1973-1913), contra uma solução autoritária para a crise social vivenciada, criticava o governo de Porfírio Díaz, reivindicando a realização de eleições justas e transparentes com a intenção de tornar o México um Estado democrático, moderno e com eleições livres (CANTARELLI; LIMA, 2003, p. 96 e 97). 
Para tais autores, a base ideológica que sustentava a revolução seria um reflexo da constituição de um pensamento moderno (o liberalismo) no cenário mexicano, o que não significava que havia uma uniformidade no processo revolucionário.

De acordo com Rampinelli, existiam duas grandes saídas para golpear o governo de Porfírio Díaz: uma revolução armada com fins socioeconômicos, defendida pelas classes médias e baixas, ou uma mudança não violenta, com fins políticos, defendida por Madero e pelos insatisfeitos das classes mais abastadas. Em suma, como afirma Marcela de Castro Tosi, em Las soldaderas: mulheres na Revolução Mexicana de 1910 (2016):

\begin{abstract}
A cena política tumultuada no México com a saída de Porfírio Díaz trouxe à tona líderes militares e políticos que queriam assumir a responsabilidade de transformar o país em uma nação moderna, cada um de acordo com seus próprios ideais. Trouxe também milhões de homens e mulheres, pessoas oprimidas há séculos, que se erguiam contra os 'inevitáveis' custos da modernização dos outros povos "atrasados", das outras raças escravizáveis, do outro sexo frágil” (TOSI, 2016, p. 149).
\end{abstract}

A partir do pontuado até aqui, percebe-se como a Revolução Mexicana fora algo que envolvera uma gama de facções sociais e políticas em luta (BARBOSA, 2006, p.19). Diante de um evento de tamanha magnitude, como o foi essa revolução, fica a pergunta: como tal temática é trabalhada nos livros didáticos de História do PNLD 2018 ?

\title{
O PNLD 2018 e o componente curricular História
}

Os livros de História utilizados para pesquisa neste artigo são os aprovados pelo Programa Nacional do Livro Didático (PNLD) 2018, que possuíam por público alvo os alunos e professores do ensino médio das escolas públicas brasileiras.

Considera-se aqui que a categoria livro didático é algo de difícil definição, tendo em vista ser uma obra bastante complexa, que se caracteriza pela interferência de vários sujeitos em sua produção, circulação e consumo (BITTENCOURT, 2008, p, 301). 
Dos autores que se aventuraram em tal intento, derivam uma gama de definições por vezes complementares, por vezes contrastantes. Oficialmente o livro didático é visto como uma ferramenta de apoio à construção dos processos educativos (BRASIL. MEC, 2017, p.9); devendo, para tanto, possuir uma leitura crítica da História (MEC, 2006, p.72). Alguns autores destacam que o livro didático sofre transformações de ordem diversa, partidas de demandas sociais, institucionais, por meio de leis, por exemplo (SOARES, 2017, p.172), constituindo-se tanto em um reflexo da política educacional do Estado, quanto um construtor de representações sociais, difundindo valores e ideologias que se refletiriam diretamente na formação identitária dos alunos (SILVA, 2011, p. 9 e 10).

Diante dessa gama de definições, adotou-se nesta pesquisa o que escreve Itamar Freitas $^{7}$

\begin{abstract}
"Livro didático", portanto, será o que decidirmos que ele for, dentro do que estabelecermos como parâmetro de uso - aquilo que ele faz ou deixa de fazer, a qualidade que porta, a finalidade que cumpre, a matéria no qual é vazado, o conteúdo que veicula, a situação que o causa e a consequência que dele provém, o lugar que ocupa no mercado, no Estado, nas instituições religiosas, militares, partidárias, nos movimentos sociais, na Universidade e na escola básica (FREITAS, no prelo).
\end{abstract}

Em se tratando do PNLD, pode-se dizer que esse é um programa existente desde 1985, sendo que em 1996 iniciou a avaliação dos manuais escolares a partir de editais trienais, cada um destinado a um nível escolar (ensino fundamental menor, ensino fundamental maior e ensino médio), o objetivo do programa seria avaliar livros didáticos e distribuí-los nas escolas públicas brasileiras. Tal processo de avaliação é constituído por algumas etapas que incluem tanto a submissão por parte das editoras de suas respectivas coleções ao edital do PNLD para serem avaliadas por especialistas de cada área, conforme as normas desse documento, quanto a produção do Guia do Livro Didático com resenhas dos materiais aprovados para as escolas públicas escolherem as coleções que melhor se

\footnotetext{
${ }^{7}$ FREITAS, Itamar. In. FERREIRA, Marieta de Morais; OLIVEIRA, Maria Margarida. Dicionário do Ensino de História. Rio de Janeiro: Fundação Getúlio Vargas, no prelo.
} 
adequem ao seu projeto político pedagógico, sendo papel do Estado efetivar a compra e distribuir aos alunos.

Observando os números disponibilizados no site do Fundo Nacional de Desenvolvimento da Educação (FNDE) ${ }^{8}$, é possível perceber que esse é um mercado cultural lucrativo, já que, por exemplo, para a compra e distribuição de livros para o ensino médio de 19.921 escolas públicas brasileiras, beneficiando cerca de 7.085.669 alunos com 89.381.588 exemplares dos livros, o governo investiu cerca de R\$ 879.770.303,13 ${ }^{9}$. Levando isso em consideração, seria de suma importância para as editoras que submeteriam suas coleções à avaliação seguir o que fora estabelecido no Edital 2018.

Com relação a tal edital, que continha os pontos a serem observados por parte das editoras para submeterem suas obras, as fotografias (abordadas mais adiante), assim como algumas outras fontes, foram consideradas como critério importante nesse processo de avaliação e seleção das obras, sendo que deveriam apresentar:

1. (...) fontes variadas quanto às possibilidades de significação histórica, como diferentes tipos de textos, sítios de internet, relatos, depoimentos, charges, filmes, fotografias, reproduções de pinturas, e indica possibilidades de exploração da cultura material e imaterial, da memória e das experiências do espaço local;

m. (...) imagens devidamente contextualizadas, acompanhadas de atividades de leitura e interpretação, referenciando sua condição de fonte para a produção do conhecimento histórico (BRASIL.MEC, 2015, p.47).

Em relação ao Manual do Professor, o recomendado era que possuísse:

c. (...) informações complementares e orientações que possibilitem a condução das atividades de leitura das imagens, sobretudo, como fontes para o estudo da história, extrapolando sua utilização como elemento meramente ilustrativo e/ou comprobatório (BRASIL.MEC,2015, p.47).

\footnotetext{
${ }^{8}$ Disponível para consulta em: https://www.fnde.gov.br data do último acesso: 28/01/20, às 17:37.

9 Fonte: FNDE. Disponível em: https://www.fnde.gov.br/programas/programas-do-livro/pnld/dadosestatisticos
} 
Desse modo, o edital deixava claro de que maneira enquadrava a imagem fotográfica que seria analisada: não como mera ilustração, mas antes como uma fonte no ofício de narrar os fatos históricos.

Ao todo foram 13 coleções aprovadas pelo PNLD 2018 para o componente curricular História, expostas no quadro a seguir:

QUADRO 1:

Coleções aprovadas no PNLD 2018

\begin{tabular}{|c|c|c|c|}
\hline Título & Autores & Edição & Editora \\
\hline $\begin{array}{l}\text { Caminhos do } \\
\text { Homem }\end{array}$ & Adhemar Marques; Flávio Beruti & $3^{\mathrm{a}}$ & Base Editorial \\
\hline Cenas da História & Cândido Grangeiro & $1^{\mathrm{a}}$ & $\begin{array}{l}\text { Palavras e Projetos } \\
\text { Editoriais }\end{array}$ \\
\hline $\begin{array}{l}\text { Conexões com a } \\
\text { História }\end{array}$ & $\begin{array}{l}\text { Alexandre Alves; Letícia Fagundes } \\
\text { de Oliveira }\end{array}$ & $3^{\mathrm{a}}$ & Moderna \\
\hline \#Contato História & $\begin{array}{l}\text { Adriana Machado Dias; Keila } \\
\text { Grinberg; Marco Pellegrini }\end{array}$ & $1^{\mathrm{a}}$ & Quinteto \\
\hline História & $\begin{array}{l}\text { Georgina dos Santos; Jorge Ferreira; } \\
\text { Ronaldo Vainfas; Sheila de Castro } \\
\text { Faria }\end{array}$ & $3^{a}$ & Saraiva Educação \\
\hline $\begin{array}{l}\text { História- das } \\
\text { Cavernas ao } \\
\text { Terceiro Milênio }\end{array}$ & $\begin{array}{l}\text { Myriam Becho Mota; Patrícia Ramos } \\
\text { Braick }\end{array}$ & $4^{\mathrm{a}}$ & Moderna \\
\hline História em Debate & $\begin{array}{l}\text { Renato Mocellin; Rosiane de } \\
\text { Camargo }\end{array}$ & $4^{\mathrm{a}}$ & Editora do Brasil \\
\hline História Global & Gilberto Cotrim & $3^{a}$ & Saraiva Educação \\
\hline $\begin{array}{l}\text { História- Passado e } \\
\text { Presente }\end{array}$ & Gislane Azevedo; Reinaldo Seriacopi & $1^{\mathrm{a}}$ & Ática \\
\hline $\begin{array}{l}\text { História, Sociedade } \\
\text { \& Cidadania }\end{array}$ & Alfredo Boulos Júnior & $2^{\mathrm{a}}$ & FTD \\
\hline Oficina de História & $\begin{array}{l}\text { Flávio de Campos; Júlio Pimentel } \\
\text { Pinto; Regina Claro }\end{array}$ & $2^{a}$ & Leya \\
\hline $\begin{array}{l}\text { Olhares da História- } \\
\text { Brasil e Mundo }\end{array}$ & Bruno Vicentino; Cláudio Vincentino & $1^{\mathrm{a}}$ & Scipione \\
\hline $\begin{array}{l}\text { Por dentro da } \\
\text { História }\end{array}$ & $\begin{array}{l}\text { Célia Cerqueira; Maria Aparecida } \\
\text { Pontes; Pedro Santiago }\end{array}$ & $4^{\mathrm{a}}$ & Escala Educacional \\
\hline
\end{tabular}

Quadro elaborado pela autora. 
Antes de entender como a temática da Revolução Mexicana foi trabalhada pelos autores em cada obra, faz-se necessário compreender como eles estruturaram suas coleções quanto à proposta curricular, já que de acordo com as Orientações Curriculares para o Ensino Médio ${ }^{10}$, um dos documentos que nortearam a confecção do Edital 2018 e a avaliação das obras, os conteúdos de História poderiam ser trabalhados por uma gama de propostas curriculares, tais como:

a) o exemplo clássico de organização dos conteúdos (...) a partir das temporalidades. (...) História Antiga, Medieval, Moderna e Contemporânea (...). Retrocede-se às origens, estabelecendo-se trajetórias homogêneas do passado ao presente (...) o que caracteriza a organização dos conteúdos, nesse contexto, é a linearidade e a seqüencialidade;

b) (...) História integrada (...) América e Brasil figuram junto a povos da préhistória, da Europa e da Ásia, fazendo-se presente, por vezes, a História da África. Nota-se em grande parte dos livros didáticos que optam por essa forma de organizar os conteúdos de História uma diminuição considerável dos assuntos referentes ao Brasil e pouquíssimo ou nenhum espaço para a História da África;

c) (...) temas selecionados ou eixos temáticos, esperando-se maior liberdade e criatividade por parte dos professores. (...);

d) (...) uma via intermediária: mantém-se a opção pela exposição cronológica dos eventos históricos consagrados pela historiografia, mas agora intercalada ou informada por exercícios e atividades chamados estratégicos (...) Aproximam-se assim as preocupações com a seqüencialidade dos conteúdos e as finalidades da educação na formação de indivíduos conscientes e críticos, com autonomia intelectual;

e) outra construção possível, algumas vezes praticada, consiste em manter, como fio organizador, a periodização consagrada como "pano de fundo" (...) A estruturação temática possibilita discussões de ordem historiográfica em diferentes períodos históricos e abre a possibilidade de se considerarem os momentos históricos na dimensão da sucessão, da simultaneidade, das contradições, das rupturas e das continuidades (...) (MEC, 2006, p. 88 e 89).

Com relação à proposta curricular e a compreensão do que viria a ser História, ou qual a utilidade de seu estudo, em cada uma das coleções, apresenta-se o quadro a seguir:

\footnotetext{
${ }^{10}$ MEC. Orientações Curriculares para o Ensino Médio- Ciências Humanas e suas Tecnologias. Brasília,
} vol. 3, 2006 . 
QUADRO 2:

Perfil de cada coleção aprovada para História - PNLD 2018

\begin{tabular}{|c|c|c|}
\hline Coleção & Proposta curricular & Compreensão da História \\
\hline Caminhos do Homem & Cronologia sequencial & $\begin{array}{l}\text { História seria um eficaz instrumento para a } \\
\text { formação de uma geração mais consciente, } \\
\text { contribuindo para uma sociedade mais justa e mais } \\
\text { humana }\end{array}$ \\
\hline Cenas da História & Cronologia sequencial & $\begin{array}{l}\text { A História seria um instrumento de construção da } \\
\text { cidadania }\end{array}$ \\
\hline \#Contato História & Cronologia sequencial & $\begin{array}{l}\text { O conhecimento histórico estaria em permanente } \\
\text { construção, aberto à multiplicidade de fontes e } \\
\text { análises }\end{array}$ \\
\hline $\begin{array}{c}\text { Conexões com a } \\
\text { História }\end{array}$ & História Integrada & $\begin{array}{l}\text { História seria um instrumento para inserir o } \\
\text { educando neste mundo como cidadão crítico e } \\
\text { autônomo }\end{array}$ \\
\hline História & História Integrada & $\begin{array}{l}\text { A História seria um conhecimento humanista que } \\
\text { contribui para a formação do estudante enquanto } \\
\text { cidadão }\end{array}$ \\
\hline $\begin{array}{l}\text { História- das Cavernas } \\
\text { ao Terceiro Milênio }\end{array}$ & História Integrada & $\begin{array}{l}\text { A História contribuiria para a formação de pessoas } \\
\text { conscientes dos problemas sociais do seu tempo e } \\
\text { das mudanças necessárias para superá-los, } \\
\text { comprometidas com princípios de tolerância, } \\
\text { democracia, paz e solidariedade }\end{array}$ \\
\hline História em Debate & Eixo Temático & $\begin{array}{l}\text { A História ocuparia um espaço privilegiado na } \\
\text { reflexão sobre o exercício da cidadania e a } \\
\text { afirmação de identidades coletivas assentadas em } \\
\text { determinada memória socialmente construída }\end{array}$ \\
\hline História Global & História Integrada & $\begin{array}{l}\text { O entendimento da História seria algo contínuo, } \\
\text { passível de se desenvolver por vários caminhos }\end{array}$ \\
\hline
\end{tabular}




\begin{tabular}{|c|c|c|}
\hline $\begin{array}{l}\text { História- Passado e } \\
\text { Presente }\end{array}$ & História Integrada & $\begin{array}{l}\text { A História teria um papel fundamental na } \\
\text { construção de um mundo mais solidário, fraterno } \\
\text { e tolerante }\end{array}$ \\
\hline $\begin{array}{l}\text { História, Sociedade \& } \\
\text { Cidadania }\end{array}$ & História problema & $\begin{array}{l}\text { A História seria um conhecimento em permanente } \\
\text { construção, necessário para desenvolver uma } \\
\text { consciência crítica. }\end{array}$ \\
\hline Oficina de História & Eixo Temático & $\begin{array}{l}\text { O saber histórico teria implicações políticas e } \\
\text { ideológicas }\end{array}$ \\
\hline $\begin{array}{l}\text { Olhares da História- } \\
\text { Brasil e Mundo }\end{array}$ & História Integrada & $\begin{array}{l}\text { A História teria papel fundamental na ampliação } \\
\text { dos direitos e da cidadania }\end{array}$ \\
\hline Por dentro da História & História Integrada & $\begin{array}{l}\text { A História desenvolveria uma consciência acerca } \\
\text { do mundo contemporâneo, com base na reflexão } \\
\text { do passado }\end{array}$ \\
\hline
\end{tabular}

Fonte: BARROS, 2019, p. 47 e 48.

De forma sintética, e em valores aproximados, percebe-se que 54\% das coleções aprovadas no componente curricular História para o PNLD 2018, adotam por proposta curricular a História Integrada, o que, de acordo com as Orientações Curriculares de História para o Ensino Médio, resultaria em uma diminuição considerável dos assuntos relacionados ao Brasil e à África, por exemplo; $23 \%$ das coleções aprovadas optaram pela proposta curricular da Cronologia Sequencial, em uma via mais intermediária, já que intercalam a exposição linear do conhecimento com atividades para o discente; $15 \%$ das coleções optaram por seguir a proposta curricular de Eixos Temáticos, o que, na teoria, forneceria ao docente maior liberdade no processo, e em $8 \%$ dos casos optou-se pela História Problema. Com relação à compreensão da História por parte das coleções aprovadas, percebe-se que a maioria, 62\%, a associam de alguma maneira à formação cidadão do discente (BARROS, 2019, p. 48 e 49). 
Com relação à temática Revolução Mexicana, nem todos os autores a trabalham em suas obras ${ }^{11}$, conforme o quadro a seguir:

QUADRO 3:

Coleções do PNLD 2018 em que os autores abordam a temática "Revolução Mexicana"

\begin{tabular}{|l|l|c|}
\hline \multicolumn{1}{|c|}{ Titulo da coleção } & \multicolumn{1}{|c|}{ Capítulo } & Página \\
\hline Cenas da História & $\begin{array}{l}\text { 13 - "O nascimento do } \\
\text { Terceiro Mundo", tópico 5 } \\
\text { "América Latina"; } \\
\text { subtópico "México } \\
\text { Revolucionário" }\end{array}$ & $240-241$ \\
\hline Conexões com a História & $\begin{array}{l}\text { 3- "A Revolução } \\
\text { Mexicana e a Revolução } \\
\text { Russa" }\end{array}$ & $45-47$ \\
\hline História & $\begin{array}{l}\text { 11- "América Latina: } \\
\text { desenvolvimento, } \\
\text { democracia e ditadura", } \\
\text { tópico 2 "Revoluções no } \\
\text { México" }\end{array}$ & $38-42$ \\
\hline Por dentro da História & $\begin{array}{l}\text { 10 - "América: revoluções } \\
\text { e contra revoluções" }\end{array}$ & $143-145$ \\
\hline
\end{tabular}

Quadro elaborado para este artigo

${ }^{11}$ Levantamento feito a partir do exposto no sumário de cada uma das coleções. 
Percebe-se que há uma liberdade, por parte dos autores, no que se refere a apresentar tal temática em suas obras, já que enquanto coleções como Conexões com a História apresentam o assunto em um capítulo específico, outras como Cenas da História o insere no contexto muito mais amplo dos países do Terceiro Mundo. Já com relação a quais fatos foram trabalhados, relacionados ao processo revolucionário, em cada obra, expõe-se a tabela a seguir:

TABELA 1:

Temas e frequência relacionados à Revolução Mexicana nas coleções do PNLD 2018

\section{COLEÇÕES DO PNLD 2018 QUE TRABALHAM A TEMÁTICA REVOLUÇÃ̃O MEXICANA}

\begin{tabular}{|c|c|c|c|c|c|}
\hline $\begin{array}{l}\text { PONTOS } \\
\text { OBSERVADOS }\end{array}$ & $\begin{array}{c}\text { Cenas Da } \\
\text { História }\end{array}$ & $\begin{array}{l}\text { Conexões } \\
\text { com a } \\
\text { História }\end{array}$ & História & $\begin{array}{l}\text { Oficina de } \\
\text { História }\end{array}$ & $\begin{array}{l}\text { Por dentro da } \\
\text { História }\end{array}$ \\
\hline $\begin{array}{l}\text { Conceito para } \\
\text { revolução }\end{array}$ & - & $\mathrm{X}$ & - & - & - \\
\hline $\begin{array}{l}\text { Situação das } \\
\text { terras comunais }\end{array}$ & $\mathrm{X}$ & $\mathrm{X}$ & $X$ & $\mathrm{X}$ & $\mathrm{X}$ \\
\hline $\begin{array}{l}\text { Economia } \\
\text { mexicana }\end{array}$ & $\mathrm{X}$ & $\mathrm{X}$ & $\mathrm{X}$ & $\mathrm{X}$ & $\mathrm{X}$ \\
\hline $\begin{array}{l}\text { Sociedade } \\
\text { mexicana }\end{array}$ & $\mathrm{X}$ & $\mathrm{X}$ & $\mathrm{X}$ & $X$ & $\mathrm{X}$ \\
\hline $\begin{array}{l}\text { Governo de } \\
\text { Porfírio Díaz }\end{array}$ & $\mathrm{X}$ & $\mathrm{X}$ & $\mathrm{X}$ & $\mathrm{X}$ & $\mathrm{X}$ \\
\hline $\begin{array}{l}\text { Marco } \\
\text { temporal da } \\
\text { revolução }\end{array}$ & $\mathrm{X}$ & $\mathrm{X}$ & $\mathrm{X}$ & $X$ & $\mathrm{X}$ \\
\hline Oposição a Díaz & $\mathrm{X}$ & $\mathrm{X}$ & $\mathrm{X}$ & $X$ & $\mathrm{X}$ \\
\hline $\begin{array}{l}\text { Prisão e fuga de } \\
\text { Madero }\end{array}$ & $\mathrm{X}$ & $\mathrm{X}$ & $\mathrm{X}$ & $\mathrm{X}$ & $\mathrm{X}$ \\
\hline $\begin{array}{l}\text { Plano San Luís } \\
\text { Potosí }\end{array}$ & - & - & $\mathrm{X}$ & $\mathrm{X}$ & - \\
\hline $\begin{array}{l}\text { Derrubada de } \\
\text { Díaz }\end{array}$ & $\mathrm{X}$ & $\mathrm{X}$ & $X$ & $\mathrm{X}$ & $\mathrm{X}$ \\
\hline
\end{tabular}




\begin{tabular}{lccccc}
\hline $\begin{array}{l}\text { Golpe de } \\
\text { Huerta }\end{array}$ & $\mathrm{X}$ & $\mathrm{X}$ & $\mathrm{X}$ & - & $\mathrm{X}$ \\
\hline $\begin{array}{l}\text { Personagens: } \\
\text { Zapata e Villa }\end{array}$ & $\mathrm{X}$ & $\mathrm{X}$ & $\mathrm{X}$ & $\mathrm{X}$ & $\mathrm{X}$ \\
\hline $\begin{array}{l}\text { Plano Ayala } \\
\text { Plano de } \\
\text { Guadalupe }\end{array}$ & - & $\mathrm{X}$ & - & - & $\mathrm{X}$ \\
\hline $\begin{array}{l}\text { Carranza no } \\
\text { poder }\end{array}$ & $\mathrm{X}$ & - & $\mathrm{X}$ & - & - \\
\hline $\begin{array}{l}\text { Constituição de } \\
\text { 1917 }\end{array}$ & $\mathrm{X}$ & $\mathrm{X}$ & $\mathrm{X}$ & - & $\mathrm{X}$ \\
\hline $\begin{array}{l}\text { Partido } \\
\text { Nacional } \\
\text { Revolucionário }\end{array}$ & $\mathrm{X}$ & - & $\mathrm{X}$ & $\mathrm{X}$ & $\mathrm{X}$ \\
\hline $\begin{array}{l}\text { Participação } \\
\text { das mulheres } \\
\text { na revolução }\end{array}$ & - & $\mathrm{X}$ & - & $\mathrm{X}$ \\
\hline \begin{tabular}{l} 
Tabela elaborada pela autora para este artigo. \\
\hline
\end{tabular} & & $\mathrm{X}$ & - & $\mathrm{X}$ \\
\hline
\end{tabular}

Tabela elaborada pela autora para este artigo.

\section{Coleção Cenas da História}

O autor Cândido Grangeiro traz a temática da Revolução Mexicana no capítulo 13 da obra, intitulado $O$ nascimento do Terceiro Mundo, inserindo-a em um contexto de luta contra a dominação estrangeira. Na introdução são trabalhados o cenário europeu do final do século XIX e a imagem que se possuía em relação a outros povos, marcada pelo etnocentrismo, o que acabava por legitimar a colonização, estabelecendo assim o preconceito contra as populações colonizadas (p. 227).

No primeiro tópico do capítulo, intitulado Dominados em insurgência, o autor menciona o termo Terceiro Mundo para se referir à África, à Ásia e à América submetidas à política de exploração das potências imperialistas, mas onde havia grupos que contestavam esse domínio imperialista, buscando soluções para os "enormes problemas decorrentes da dominação colonial” (p. 228).

No tópico 5, intitulado América Latina, a temática ligada à revolução foi trabalhada de forma específica. Grangeiro inicia esse tópico mencionando que haveria 
uma semelhança entre os países da América Latina e os africanos e asiáticos (abordados em tópicos anteriores): um longo histórico de dominação europeia. A diferença seria que, neste continente, a dominação teria começado e terminado antes dos demais (p.239).

O autor inicia o subtópico México revolucionário apresentando a sociedade mexicana do início do século XX, formada por indígenas e mestiços, que se concentravam no campo com uma crescente redução de terras comunais. Seguindo a narrativa, Grangeiro apresenta o governo de Porfírio Díaz (1830-1915), que "mantinha-se no poder à custa de forte repressão aos opositores", e o entrave gerado quando em 1910, tentara uma nova reeleição, recebendo a oposição de Francisco Madero que, ao prometer amplas reformas, ganhara apoio popular (p.240). A isso teria se sucedido um período de profunda instabilidade, que se estenderia até 1920 e ficaria conhecido como Revolução Mexicana.

A narrativa factual prossegue, abordando a fuga de Madero da cadeia, seu exílio nos Estados Unidos, a derrubada de Díaz do poder, e como aquele não conseguiu, ao assumir o controle, dar uma solução aos principais problemas do país.

Citam-se os movimentos populares que ganhavam destaque no campo, o Exército Libertador do Sul liderado por Zapata (1879-1919), e a Divisão do Norte comandada por Pancho Villa (1878-1923), além de como o movimento do Sul começou a ganhar força com a "luta pela recuperação das terras comunais" (p.240).

Grangeiro prossegue trabalhando o golpe de estado, o assassinato de Madero e a posse, em 1913, de Vitoriano Huerta (1850-1916), o que levaria o México a uma guerra civil e intensificaria o movimento camponês do norte do país. Venustiano Carranza (18591920), governador de um dos estados do Norte, é apresentado como aquele que se oporia ao governo de Huerta e recorreria a Pancho Villa, apoiador de Madero, que "comandava um exército de 10 mil homens, formado em sua maioria por camponeses e vaqueiros" (p.240).

O autor afirma que, em 1914, Carranza derrotaria Huerta e assumiria o poder, adotando uma política para "esvaziar os movimentos populares", anunciando a reforma agrária. Menciona-se ainda a promulgação da Constituição em 1917, os assassinatos de 
Zapata e de Villa, e a destituição sem resistência de Carranza do poder, em 1920, por Álvaro Obregón (1880-1928), chegando ao fim a Revolução Mexicana.

Para o autor, tal revolução teria implantado profundas transformações no México, como a redução da importância do capital estrangeiro e a garantia de ganhos sociais com a Constituição de 1917, sem, contudo, superar muitos problemas do país.

Por fim, menciona-se que no governo de Obregón, a situação interna mexicana ganhou estabilidade, e um único partido se imporia no cenário político, o Partido Nacional Revolucionário (PNR), depois Partido Revolucionário Institucional (PRI), que permaneceria no poder até o início do século XXI (p.241).

\section{Coleção Conexões com a História}

Os autores Alexandre Alves e Letícia Fagundes de Oliveira abordam a temática da Revolução Mexicana no capítulo 3 de sua obra, intitulado A Revolução Mexicana e a Revolução Russa, objetivando, entre outras coisas, que o discente reconheça o campesinato como a base social da Revolução Mexicana, além de identificar as principais lideranças do movimento e comparar esse processo revolucionário com a Revolução Russa, em busca de suas semelhanças e diferenças.

Os autores iniciam o capítulo conceituando o termo revolução e traçando um paralelo entre o processo revolucionário mexicano e o russo, no que se refere a ambos serem revoluções sociais (uma marcou a América Latina e a outra serviria para explicar muitos episódios do século XX, respectivamente), que corroborariam para mudar as vidas de sua população, além de serem marcos dos movimentos populares na história mundial.

No tópico 3.1, México: um país com muitos conflitos, os autores iniciam apresentando a região, entre os séculos XIX e XX, como dependente do capital estrangeiro e que disputava terras e fronteiras com os Estados Unidos, com o agravamento da situação dos indígenas e camponeses, pois viviam na miséria absoluta. No meio urbano, ocorreriam greves por melhorias salariais e diminuição da jornada de trabalho, por 
exemplo. Nesse contexto, os autores escrevem que "em 1910, deflagrou-se a Revolução Mexicana, um dos maiores movimentos populares desde o período das revoluções europeias de 1830-1871" (p.45).

A extrema desigualdade é apresentada como um fator que teria se agravado no governo de Porfírio Diaz, entre 1876 e 1911, tendo em vista a expropriação de terras dos camponeses em 1890.

Fagundes e Oliveira enfatizam a situação das terras, apontando que, em 1910, cerca de $90 \%$ dos camponeses, por não terem terras, se viam obrigados a trabalharem nos latifúndios. Naquele ano, sob o lema "Terra e Liberdade", se iniciaria uma rebelião camponesa, com o objetivo de conseguir melhores condições de vida e de trabalho.

Os autores também abordam a crise econômica de 1907-1911, que reduziria o apoio ao governo de Díaz, e faria com que os antiporfirirstas se organizassem desde o início daquele século em clubes democráticos.

Intitulado Os líderes Madero, Villa e Zapata, o tópico seguinte trabalha essas três personagens que seriam responsáveis, para os autores, por pelo menos três focos da revolução, afirmando que "o movimento revolucionário organizou-se por meio de uma aliança entre os camponeses e parte dos setores modernos e liberais das cidades" e que a "progressiva radicalização do campesinato e o aprofundamento das críticas de liberais e da esquerda operária transformaram uma luta por liberdades civis e justiça social em uma revolução social armada" (p.46).

O tópico seguinte se relaciona ao governo de Madero, descrito como aquele que procurou se equilibrar entre as pressões dos diversos grupos e que não conseguiu atender as exigências das camadas mais pobres (p.46). Menciona-se o lançamento do Plano de Ayala, em 1911 por Zapata, que serviria como referência à luta dos camponeses no México por mais dez anos.

O parágrafo seguinte traz o golpe contra o governo de Madero e a figura de Huerta, que passaria a combater a insurreição dos camponeses. Haveria para os autores um período de instabilidade política depois disso, seguido pela queda de Huerta e o governo 
de Carranza, legitimado pela Constituição de 1917, porém enfraquecido posteriormente por falta de apoio, sendo assassinado em 1920. Os autores encerram o assunto falando das mortes de Zapata, em 1919, e de Villa, em 1923, mencionando que a captação dos exércitos camponeses pelo governo, no ano seguinte, marcaria o fim do processo revolucionário (p.47).

\section{Coleção História}

Georgina dos Santos, Jorge Ferreira, Ronaldo Vainfas e Sheila de Castro Faria, autores da coleção, trazem a temática da Revolução Mexicana em sua obra no capítulo 11, intitulado América Latina: desenvolvimento, democracia e ditadura, que teria por objetivo estudar a região no período compreendido entre os anos de 1960 e 1970.

No primeiro tópico desse capítulo, América Latina: nacionalismo e desenvolvimentismo, os autores apresentam a América Latina (os países Brasil, Venezuela, Colômbia, Argentina, Chile e México, por exemplo) como de economias agroexportadoras, que beneficiavam as elites em detrimento de amplos setores da população que viviam em condições miseráveis. Tal modelo seria gerador de dependência econômica em relação aos Estados Unidos e à Europa Ocidental.

Os autores afirmam que setores das elites estariam insatisfeitos com tal dependência e julgavam que, para superá-la, juntamente às desigualdades internas seria "necessário alterar a economia baseada na exportação de produtos agrícolas e minerais e formular um projeto de desenvolvimento baseado na industrialização" (p.138). Para tanto, a opção seria recorrer ao capital privado e a empréstimos estrangeiros em um projeto de caráter estatizante e nacionalista denominado na obra de desenvolvimentismo.

O tópico seguinte, Revolução no México, se inicia com os autores afirmando que diversas teriam sido as vias para o desenvolvimentismo na América Latina: "revoluções, regimes liberais-democráticos, ditaduras militares" (p.184). Para os autores, a Revolução Mexicana inauguraria "políticas desenvolvimentistas que serviriam de modelo para outros países latino-americanos" (p.184). 
Em seguida, os autores pontuam que, no início do século XX, começaram a surgir críticas ao governo de Porfírio Díaz, por este estar no poder há mais de 30 anos manipulando as eleições. Seu governo beneficiaria apenas latifundiários e empresários, enquanto os trabalhadores urbanos e rurais enfrentavam muitas dificuldades, estando os últimos revoltados por terem perdido terras para os grandes latifúndios.

Apresenta-se Francisco Madero, as eleições e o seu exílio nos Estados Unidos. Menciona-se o Plano San Luís Potosí, que incitaria o povo a revolta e, por fazer uma vaga referência à distribuição de terras aos camponeses, receberia o apoio de líderes rurais como Pancho Villa e Emiliano Zapata.

Na sucessão de datas e fatos, os autores da obra trabalham a aclamação de Madero, sua eleição em 1911, a falta de preocupação do seu governo com as injustiças sociais e sua deposição em 1913 por Huerta.

No subtópico Projetos revolucionários, Santos, Ferreira, Vainfas e Faria apresentam a revolução como dividida em pelo menos três projetos: Zapata, Villa e Carranza. É dito que este, em 1913, lança o Plano de Guadalupe - um programa para combater o governo de Huerta, que instituía um exército constitucionalista, e com o apoio de Zapata e Villa deporia o governo em 1914.

No subtópico seguinte, Novos conflitos, os autores abordam a guerra civil entre as três lideranças. Menciona-se que em 1915, Carranza decretou a reforma agrária, "iniciando" a devolução de terras aos camponeses, aliou-se a maior central sindical mexicana, a Casa do Operário Mundial e, apoiando as lutas dos trabalhadores urbanos, derrotou as tropas camponesas villistas e zapatistas, encerrando as guerras civis no México.

Por fim, no subtópico seguinte, A revolução continuada, os autores escrevem que, com o objetivo de institucionalizar a revolução, o governo de Carranza convoca uma Assembleia Constituinte e, em 1917, o México ganha uma nova Constituição, com inovações como leis sociais e uma legislação agrária. Tal constituição, juntamente à formação do Partido Revolucionário Institucional, o PRI, encerraria e consolidaria, para 
os autores, o processo revolucionário iniciado em 1910, fazendo o México entrar em uma estabilidade política. Para eles, entre os governos que se declararam herdeiros da revolução, o mais inovador seria o de Lázaro Cárdenas (1934-1940) por, entre outras coisas, ter estendido a reforma agrária e inaugurado uma série de políticas desenvolvimentistas.

\section{Coleção Oficina de História}

Os autores Flávio de Campos, Júlio Pimentel Pinto e Regina Claro apresentam nessa coleção a temática da Revolução Mexicana inserida no capítulo 1, intitulado Guerra e revolução, objetivando apresentar o contexto revolucionário marcado por questões camponesas e, por conseguinte, o contexto latino-americano no princípio do século XX, antecedido, no referido capítulo, pela abordagem da temática da Primeira Guerra Mundial e da Revolução Russa.

Os autores iniciam o tópico 3 relacionado à temática, intitulado A Revolução Mexicana, apresentando o surgimento da expressão "América Latina”, em meados do século XIX, para designar o território de colonização espanhola, sendo que, com o passar do tempo, o termo passou a ser utilizado como forma de rejeitar qualquer controle estadunidense na região.

Ao lado de uma linha do tempo da revolução no México, que abrange desde 1876 a 1994, os autores iniciam o tópico A ditadura de Porfírio Díaz buscando traçar um breve histórico do México que, desde o período colonial, teria enfrentado sérias disputas de terras. Aponta-se que, mesmo independente, persistia no país uma concentração de terras nas mãos de grandes proprietários.

Ainda na temática de terras, ao falar do governo de Díaz, menciona-se como ele estimulou o processo de expropriação das terras indígenas e camponesas. Os autores versam ainda sobre a economia do país durante o seu mandato, voltada à exportação, e sobre a política interna, favorecedora dos grandes latifundiários. 
No subtópico seguinte, Descontentamento e resistência, os autores Campos, Pinto e Claro, de maneira fluida e para além de uma abordagem factual, destacam a criação do Partido Liberal no início do século XX, por um grupo de intelectuais, dando destaque à circulação de ideias dentro da sociedade mexicana, como as ideias anarquistas e socialistas entre os operários insatisfeitos, e o fato destes fazerem circular suas propostas em jornais e panfletos, pelo Norte do México, por exemplo.

Na sequência, os autores abordam a agitação de camponeses e indígenas no Norte e no Sul do país, e dos setores liberais burgueses, também contrários ao porfirismo, contextualizando uma insatisfação generalizada que existiria na sociedade prérevolucionária.

No tópico A Hora da Revolução, os autores mencionam a candidatura de Madero, em 1910, à presidência, sua derrota em eleições fraudulentas, e a divulgação do Plano de San Luís de Potosí, conclamando o povo à revolução em 20 de novembro, que teria a adesão das tropas camponesas de Pascual Orozco (1882-1915), Pancho Villa (1878-1923) e Zapata (1879-1919), além de mineiros e operários em um México que se rebelava (p.40).

Após tratar da renúncia de Díaz e da eleição de Madero à presidência, os autores dão um salto para abordarem a Constituição de 1917. Não se trabalha o golpe de Huerta, nem o de Carranza, o que confirma a opção dos autores em não trabalhar a temática por um viés factual. O grande problema talvez resida no fato de os autores também deixarem de trabalhar as disputas internas que existiram em torno dos rumos do processo revolucionário mexicano, o que acabaria por passar uma visão de unanimidade em torno da Revolução.

Nesse tópico, intitulado A Constituição de 1917, apresentam-se algumas garantias da Constituição, como o ensino laico, o prevalecimento de propostas liberais, a limitação da jornada de trabalho e a regularização do trabalho infantil e feminino, por exemplo. Mas, para Campos, Pinto e Claro, a grande novidade seria o artigo 27, que tratava do setor rural. Afirma-se que, por conta dele, muitas pessoas receberam terras, porém não teriam conseguido mantê-las por falta de apoio governamental. 
No tópico seguinte, A simples verdade, os autores trabalham as figuram emblemáticas de Villa e Zapata. Em A arte da Revolução, apresentam algumas das muitas maneiras utilizadas para representar a Revolução Mexicana, durante e depois da luta: pintura, canções e fotografia, por exemplo. Interessante notar que a utilização da fotografia é apresentada com destaque, mas os autores não trazem fotografia alguma relacionada à temática em sua obra. Apresentam um link para a Fototeca Nacional do México, que, ao tentar ser acessado, acusa erro.

Os autores Campos, Pinto e Claro apresentam em um box intitulado As mulheres revolucionárias, a participação feminina no processo revolucionário. Mencionam, mas não problematizam, a presença em quase todas as fileiras revolucionárias das "soldaderas" ou “Adelitas", cujos objetivos, como o voto feminino, não foram atendidos.

\section{Coleção Por dentro da História}

Célia Cerqueira, Maria Aparecida Pontes e Pedro Santiago, autores da coleção, trazem a temática da Revolução Mexicana no capítulo 10, intitulado América: revoluções e contrarrevoluções, cujo objetivo seria conhecer os governos populistas da América Latina e seus projetos nacionalistas, que marcariam o século XX na tentativa de estabelecer um caminho próprio para os povos do continente.

No primeiro tópico do capítulo, intitulado Os países latino-americanos após a independência, os autores apresentam a América Latina como uma região marcada pela diversidade dos povos, mas que estes possuiriam pontos comuns na história até o processo de independência, no início do século XIX. Além disso, um modesto crescimento econômico voltado à exportação, instabilidades políticas internas e externas, interferências estrangeiras, uma elite detentora do poder e uma situação que pouco ou quase nada mudava para os habitantes do campo e das zonas de mineração. Os autores mencionam que durante a Segunda Guerra Mundial (1939-1945), intensificaram-se na região parques industriais e que, ao final do conflito, ela estaria aberta para empresas e investimentos estrangeiros. 
No tópico seguinte, México: um longo processo, os autores contextualizam o início do século XX mexicano, com um governo de Porfírio Díaz, "estável” no campo político (já que, para eles, tal governo teria "sufocado" a oposição), dependente do capital externo, que privilegiava as elites e possuía uma economia voltada à exportação, mas que era marcado pela má distribuição de terras, apresentada como um dos principais problemas do país.

O ano de 1910 é trabalhado com a tentativa de reeleição de Díaz, contando com a oposição de Madero que, prometendo amplas reformas, ganharia apoio popular. Para os autores, seria com a prisão de Madero e sua posterior fuga para comandar um movimento pela derrubada de Díaz que começaria a Revolução Mexicana, marcada, para eles, por intensos conflitos e disputas pelo poder que se estenderia até 1920.

Fatos como a deposição de Porfírio Díaz, o governo de Madero e sua falha em solucionar os problemas sociais do país são também trabalhados no capítulo, assim como no subtópico intitulado Os camponeses entram na história, as figuras de Zapata e Villa o são, juntamente ao Plano de Ayala (1911), apresentado como algo que formataria o movimento revolucionário, o golpe de Huerta (1913) e o início de uma guerra civil.

No tópico seguinte, intitulado Os homens do Norte, os autores trabalham a derrubada de Huerta, em 1914, e a posse de Venustiano Carranza. Também abordam a Constituição de 1917, apresentando-a como avançada por incorporar conquistas sociais tais como a reforma agrária e a legislação trabalhista, que acabaria por servir para a consolidação de Carranza no poder.

Os autores afirmam que o golpe final na revolução se daria em 1919, com a morte de Zapata, seguida pela destituição de Carranza do poder (1920) e a morte de Villa (1923). Para eles, "sem nenhuma resistência chegava ao fim a Revolução Mexicana" (p.144).

Por fim, no tópico $O$ resultado do movimento, os autores oferecem uma interpretação para a revolução e apontam como a Constituição de 1917 não conseguiu superar muitos dos problemas existentes no país, como a questão de terras, por exemplo (p.145). 
A partir do exposto até aqui, percebe-se que não há unanimidade entre os autores de cada uma das coleções que optaram por trabalhar a temática da Revolução Mexicana em suas obras, quanto à sua abordagem. O que há são variadas visões do processo revolucionário: algumas com um enfoque mais factual, como, por exemplo, as apresentadas nas coleções Cenas da História, História e Por dentro da História, contrapondo-se à opção feita pelos autores da coleção Oficina de História, ou mesmo da coleção Conexões com a História.

O ponto de vista pelo qual os autores narram os fatos relacionados à Revolução Mexicana também varia, predominando uma visão ligada ao político e as lutas pelo poder (coleção Por dentro da História), tendo na dianteira os "grandes homens, grandes líderes" como Díaz, Madero, Zapata, Villa, Huerta, Carranza (coleção Cenas da História), por exemplo. Na coleção História, os autores também adotam uma perspectiva de História vista "de cima para baixo", evidente quando, na página 138, dão a entender que a elite insatisfeita com a situação interna do México (e dos países da América Latina como um todo, já que os autores optam por dissolver as diferenças e apresentar uma situação em comum de todos os países) e julgavam que, para superá-la, juntamente às desigualdades internas seria necessário alterar a economia e formular um projeto de desenvolvimento baseado na industrialização. Tais versões se contrapõem à narrativa com foco para as questões sociais apresentada na coleção Conexões com a História, e a que partiria especificamente das questões camponesas para explicação do ocorrido, como na coleção Oficina de História.

Com relação ao contexto no qual a revolução ocorreria, também variadas seriam as explicações: uma luta contra a dominação externa (Cenas da História), ou uma luta para melhorar as condições das camadas mais baixas da sociedade (Conexões com a História e Oficina de História), ou mesmo uma luta para superar a dependência e as desigualdades (História e Por dentro da História).

Com relação a formular uma definição para a revolução ocorrida no México, esta também varia: um período de profunda instabilidade (Cenas da História); um dos maiores 
movimentos populares (Conexões com a História); uma via para o desenvolvimentismo (História); um período de rebelião de diversos setores mexicanos (Oficina de História); um período de conflitos e disputas pelo poder (Por dentro da História), por exemplo.

Merece destaque que, muito embora a historiografia recente reconheça a atuação das mulheres no decorrer do processo revolucionário mexicano, como aquelas que desempenharam importantes papéis que se complementariam na luta mais ampla por direitos no país, auxiliando as tropas de diversas maneiras (TOSI, 2016, p. 145), e apesar de ser uma das exigências do edital a promoção positivamente da imagem da mulher, considerando sua participação em diferentes trabalhos, profissões e espaços de poder, reforçando sua visibilidade e seu protagonismo social (BRASIL. MEC, 2015, p. 32), em apenas duas coleções haveria menção à participação feminina no processo: coleção Oficina de História, a partir do box outrora mencionado, bem como na coleção Conexões com a História, a partir de uma fotografia das revolucionárias mexicanas. Mas como esta e as demais fotografias relacionadas à temática são trabalhadas nos livros?

\section{O trabalho das fotografias da Revolução Mexicana nos livros didáticos de História do PNLD 2018}

Com relação às obras destacadas anteriormente, apenas em três delas os autores apresentam fotografias relacionadas à Revolução Mexicana, expostas a seguir com suas respectivas legendas: 


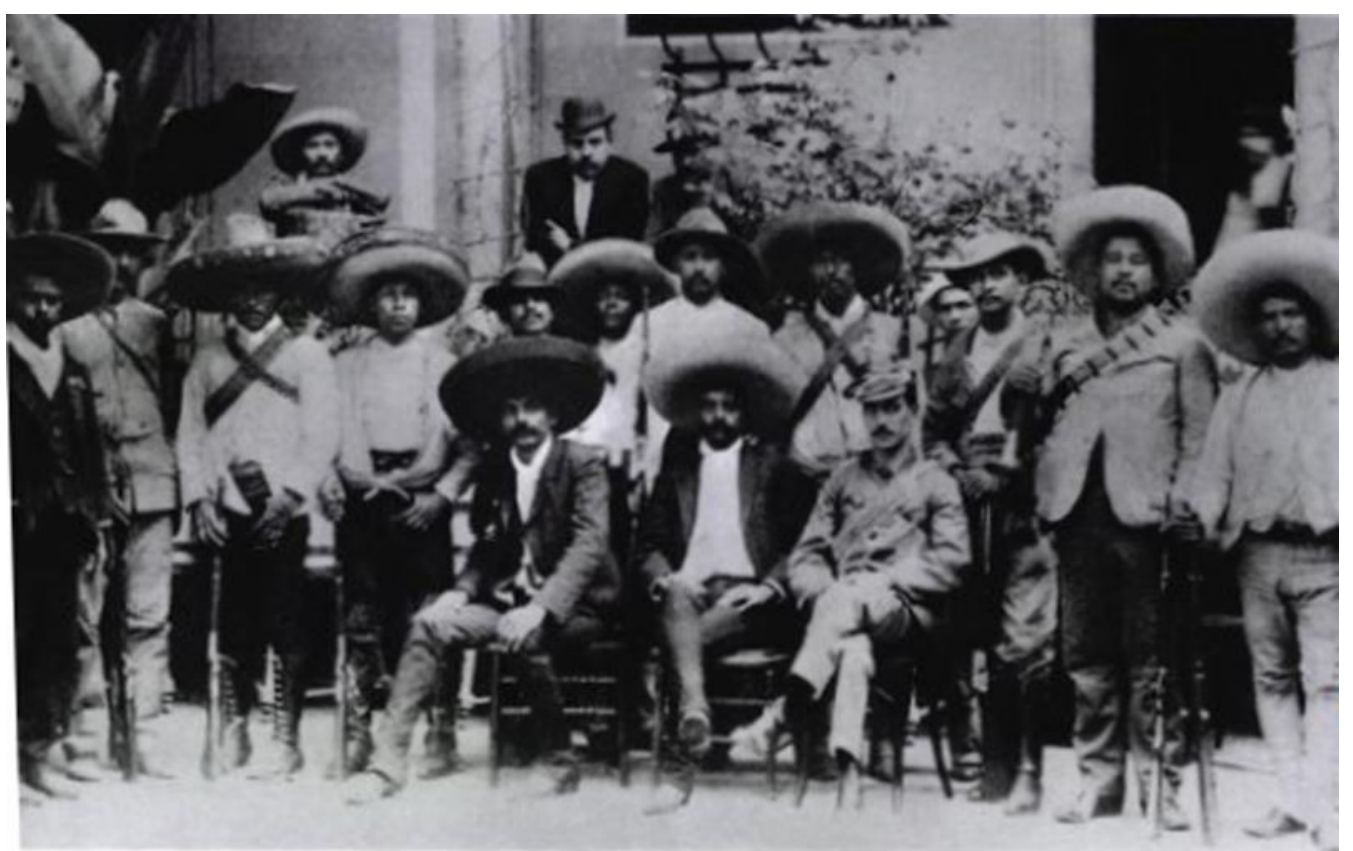

Fotografia 1: "Emiliano Zapata acompanhado de integrantes do Exército de Libertação do Sul, México, 1914”. Fonte: GRANGEIRO, 2016, p. 240.

\footnotetext{
Revista Eletrônica da
ANPHLAC

Revista Eletrônica da ANPHLAC, ISSN 1679-1061, № 28, p. 49-82, Jan./Jul., 2020.

http://revista.anphlac.org.br
} 


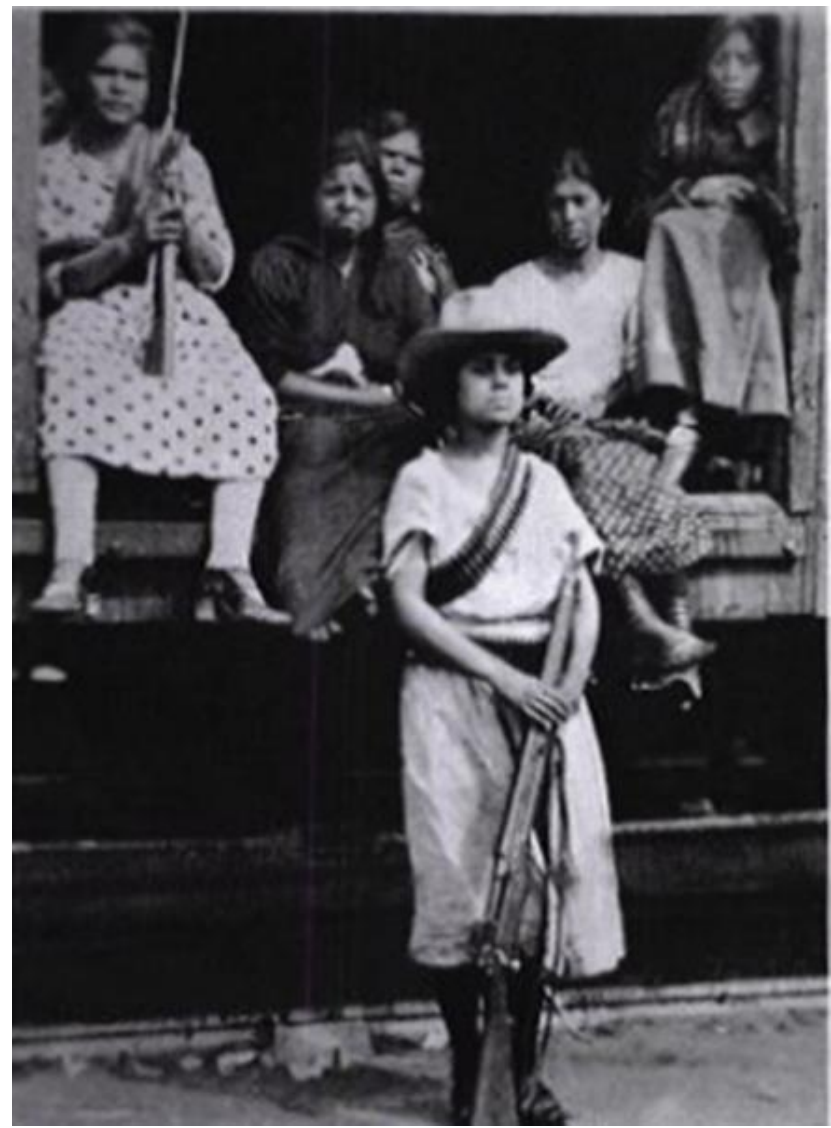

Fotografia 2: "Revolucionárias mexicanas, chamadas soldaderas. Foto da década de 1912. As mulheres também atuaram na Revolução Mexicana, colaborando tanto com as forças revolucionárias quanto com as tropas federais". Fonte: ALVES; OLIVEIRA, 2016, p. 45. 


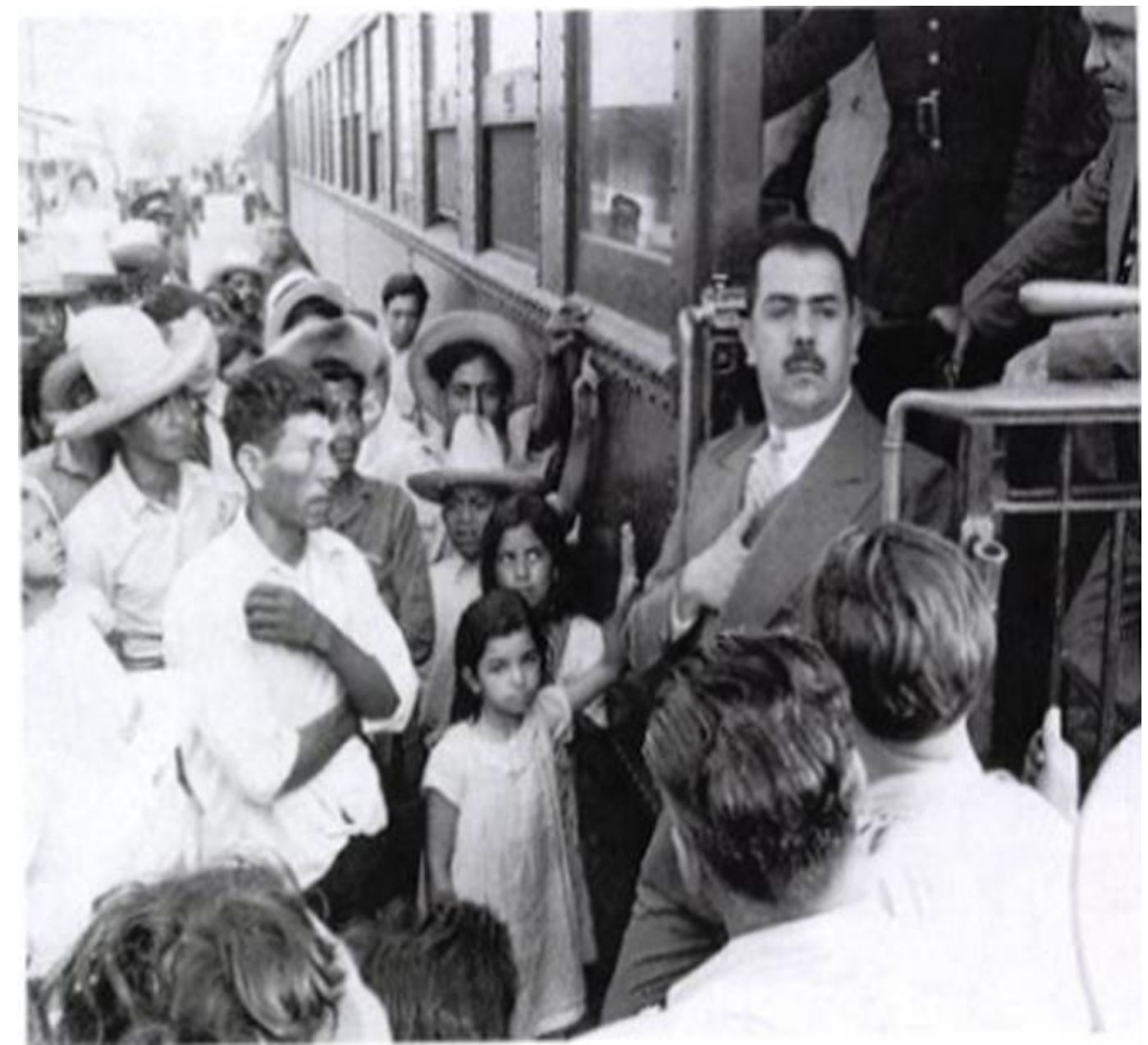

Fotografia 3: "Lázaro Cárdenas governou o México entre 1934 e 1938, realizou reformas sociais e desenvolveu políticas nacionalistas e estatizantes. Fotografia da década de 1930".

Fonte: SANTOS; FERREIRA; VAINFAS; FARIA, 2016, p. 186.

\author{
RANista Eletrônica da \\ Revista Eletrônica da ANPHLAC, ISSN 1679-1061, № 28, p. 49-82, Jan./Jul., 2020. \\ http://revista.anphlac.org.br
}


Ao submeterem suas coleções à avaliação pelo PNLD, os autores concordavam em seguir o proposto no edital, no caso das fotografias, em trabalhá-las como fontes em suas coleções, ou seja: subtendia-se que as fotografias deveriam ser trabalhadas em sua complexidade, como uma representação do real, assim como os documentos em geral que, apesar de limitados, são poderosos instrumentos para se perscrutar o passado.

Alguns autores até deixam isso claro ao final de suas obras, na parte destinada a fornecer um suporte pedagógico aos docentes, evidenciando que as imagens são entendidas, de forma genérica, como recursos didáticos importantes, em que se faz necessário estimular os alunos a uma observação atenta no que se refere à disposição dos elementos no espaço, de percepção das cores, das formas utilizadas e das condições de produção, por exemplo (coleção Cenas da História). Ou, ainda, especificamente se referindo às fotografias como um documento histórico que precisa ser contextualizado, problematizado e analisado, explicando para o professor como se daria cada uma dessas etapas (coleção História), assim evidenciando a necessidade de se estar atento a "quem está tentando nos dizer o que" (coleção Oficina de História).

Porém, quando se observam as fotografias aqui apresentadas, é perceptível que sua utilização não passa de uma ilustração nas respectivas obras. Os autores não investem em explorar a perspectiva pela qual foram registradas, por exemplo, tampouco oferecem atividades no decorrer do capítulo que colaborem para tanto.

Mesmo sendo de conhecimento geral que registrar a autoria de imagens desse tipo era algo difícil à época revolucionária, sabe-se, por exemplo, que uma família, os Casasola, se dedicou ao ofício de construir uma memória visual da Revolução Mexicana. Nos dizeres de Barbosa (2006, p. 38), durante a revolução, o público poderia acompanhar os fatos mais recentes dos movimentos bélicos através da vitrine da agência dos Casasola, nas quais se expunham as imagens. Uma dessas imagens é apresentada na coleção Conexões com a História, página 45, porém não se menciona isso. Essa fotografia é apresentada por Barbosa (2006, p.183) como sendo da Revolução Delahuertista, de 1923, que integra o álbum História Gráfica de la Revolución Mexicana, volume 5, páginas 1668- 
1669. Também não há um esforço por parte dos autores em se problematizar essa participação feminina, escrita por Tosi (2016), por exemplo:

\begin{abstract}
Embora não se saiba ao certo quantas mulheres lutaram, fizeram-no tanto em nome do governo federal quanto do lado daqueles que se opunham à ditadura (...) algumas lutaram em prol dos ideais revolucionários como a reforma agrária; outras lutaram porque os homens em suas vidas estavam lutando e elas queriam para apoiá-los. Muitas seguiam os exércitos para ter uma forma de trabalho e sustento. Algumas foram por terem sido sequestradas. Outras jovens, de doze e treze anos de idade, foram forçadas a acompanhar seus pais em guerra e mais tarde se tornaram soldaderas. Além destas, mulheres mais velhas entraram na guerra em busca de vingança pela morte ou captura de seu marido, filho ou irmão. Assim, mulheres de todas as idades participaram ativamente junto aos exércitos e por razões diversas (TOSI, 2016, p. 150).
\end{abstract}

Similarmente, também não há uma preocupação, partindo da fotografia apresentada por Santos, Ferreira, Vainfas e Faria na coleção História, página 186, em se aprofundar uma prática do governo de Cárdenas no que se refere à ênfase na política de massas, por exemplo. Possivelmente, abordar esses e outros aspectos, poderia contribuir para um melhor entendimento da temática, para além da sucessão de datas e fatos apresentados, por parte do discente.

\title{
Considerações finais
}

A Revolução Mexicana, por muitos fatores, pode ser considerada como um marco nos estudos históricos relacionados à América Latina, tendo em vista seu pioneirismo, por exemplo, o que para muitos a colocaria como o marco do início da Idade Contemporânea na região.

A partir do exposto no presente artigo, é possível perceber que, apesar de sua importância, a temática relacionada ao processo revolucionário mexicano não é trabalhada em $62 \%$ dos livros didáticos destinados ao terceiro ano do ensino médio, aprovadas para o componente curricular História no PNLD 2018, nestes que são ainda o principal recurso utilizado pelo professor nas escolas públicas brasileiras. 
Dos autores que optam por trabalhar a temática em suas coleções (38\%), percebese que a abordagem, em sua maioria, é feita sob o viés político e factual, corroborando para a disseminação de uma "história dos grandes homens" que gira em torno do poder, na qual não há espaço para as mulheres, mesmo que no edital se oriente quanto à necessidade de se promover positivamente a imagem da mulher, nas coleções que seriam submetidas à avalição, tendo em vista reforçar sua visibilidade e protagonismo social.

No que se refere às fotografias da revolução, percebe-se que, diferentemente da proposta do Edital 2018, que exigia que as coleções apresentassem informações complementares e orientações que possibilitassem a condução das atividades de leitura das imagens, sobretudo, como fontes para o estudo histórico, os autores das coleções em questão não trabalham as fotografias como fontes no decorrer das suas obras, mas como simples ilustração, conforme o exposto neste artigo, tendo em vista que estes não aprofundam ou exploram o ângulo de captura das imagens, ou o fotógrafo responsável, ou a visão de mundo contida, ou mesmo o assunto que é tratado, por exemplo. Aspectos estes que, se trabalhados, poderiam colaborar para um melhor e mais amplo entendimento da Revolução Mexicana, como um todo, por parte dos discentes.

\section{Referências Bibliográficas}

\section{Fontes}

BRASIL. MEC. Edital de Convocação 4/2015-CGPLI. Processo de Inscrição e Avaliação de Obras Didáticas para o Programa Nacional do Livro Didático - PNLD 2018. Brasília: MEC, 2015.

BRASIL. MEC. PNLD 2018: apresentação - guia de livros didáticos - ensino médio/ Ministério da Educação - Secretária de Educação Básica - SEB - Fundo Nacional de Desenvolvimento da Educação. Brasília, DF: Ministério da Educação, Secretária de Educação Básica, 2017.

MEC. Orientações Curriculares para o Ensino Médio- Ciências Humanas e suas Tecnologias. Brasília, vol. 3, 2006. 


\section{Obras aprovadas para o PNLD 2018}

ALVES, Alexandre; OLIVEIRA, Letícia Fagundes de. Conexões com a História. Salvador: Moderna, 3 ed., 2016.

AZEVEDO, Gislane; SERIACOPI, Reinaldo. História- Passado e Presente. São Paulo: Editora Ática, 2016.

CAMPOS, Flávio de; PINTO, Júlio Pimentel; CLARO, Regina. Oficina de História. Lauro de Freitas: Leya, 2 ed., 2016.

CERQUEIRA, Célia; PONTES, Maria Aparecida; SANTIAGO, Pedro. Por dentro da História. São Paulo: Escala Educacional, 4 ed., 2016.

COTRIM, Gilberto. História Global. São Paulo: Saraiva Educação, 3 ed., 2016.

DIAS, Adriana Machado; GRINBERG, Keila; PELLEGRINI, Marco. \#Contato História. Salvador: Quinteto, 2016.

GRANGEIRO, Cândido. Cenas da História. São Paulo: Palavras e Projetos Editoriais, 2016.

JÚNIOR, Alfredo Boulos. História, Sociedade \& Cidadania. Salvador: FTD, 2 ed., 2016.

MARQUES, Adhemar; BERUTI, Flávio. Caminhos do Homem. São Paulo: Base Editorial, 3 ed., 2016.

MOCELLIN, Renato; CAMARGO, Rosiane de. História em Debate. São Paulo: Editora do Brasil, 4 ed., 2016.

MOTA, Myriam Becho; BRAICK, Patrícia Ramos. História - das Cavernas ao Terceiro Milênio. Salvador: Moderna, 4 ed., 2016.

SANTOS, Georgina dos; FERREIRA, Jorge; VAINFAS, Ronaldo; FARIA, Sheila de Castro. História. São Paulo: Saraiva Educação, 3 ed., 2016. 156

VICENTINO, Bruno; VICENTINO, Cláudio. Olhares da História-Brasil e Mundo. São Paulo: Editora Scipione, 2016. 


\section{Bibliografia}

ALVES, Lourdes Kaminski. Representações literárias da Revolução Mexicana na narrativa de Juan Rulfo, Revista da Anpoll, Florianópolis, n 43, jul/dez 2017, p.135-152.

ASSUNÇÃO, Fernando Rodrigues de. O discurso identitário no México pós-revolução mexicana representado em alguns autorretratos de Frida Kahlo. Anais do XXVI Simpósio Nacional de História- ANPUH, São Paulo, julho 2001, p. 01-08.

BARBOSA, Carlos Alberto Sampaio. A fotografia a serviço de Clio: uma interpretação da história visual da Revolução Mexicana (1900-1940). São Paulo: Editora UNESP, 2006.

Ecos da Revolução Mexicana na imprensa brasileira. ANPUH- XXIII Simpósio Nacional de História, Londrina, 2005, p.01-08.

BARROS, Maria Luiza Pérola Dantas. O trabalho com as fotografias no ensino da segunda guerra mundial: um estudo comparado das coleções do PNLD 2018. 2019. f. 170 Dissertação (Mestrado em Educação) - Universidade Federal de Sergipe, São Cristóvão, SE, 2019.

BISCO JÚNIOR, José Gaspar. México insurgente: da Revolução Mexicana ao surgimento do EZLN. (Monografia) Mariana, Universidade Federal de Ouro Preto, 2003.

BITTENCOURT, Circe Maria Fernandes. Livros e materiais didáticos de História. IN Ensino de História: fundamentos e métodos. São Paulo: Cortez Editora, 2 ed, 2008, p. 295-324.

CANTARELLI, Ana Paula, LIMA, Erivelton Franco de. Em busca de uma ideologia para a Revolução Mexicana. Revista Eletrônica Literatura e Autoritarismo: Ideologia, violência e mito na literatura, n 22, julho a dezembro 2013, p.89-104.

ESPINDOLA, Julieny Oliveira; SILVA, José Santana. Revolução Mexicana: a visão dos contemporâneos Flores Magon e John Reed. IV Congresso de Ensino, Pesquisa e Extensão da UEG 2018, p. 01-08.

FREITAS, Itamar. In. FERREIRA, Marieta de Morais; OLIVEIRA, Maria Margarida. Dicionário do Ensino de História. Rio de Janeiro: Fundação Getúlio Vargas, no prelo.

KOSSOY, Boris. Realidades e Ficções na trama fotográfica. São Paulo: Ateliê Editorial, 4 ed., 2009. 
MATOS, Júlia Silveira; SENNA, Adriana Kivanski de. Estado, editoras e ensino: o papel da política na produção, avaliação e distribuição dos livros didáticos de História no Brasil (1938-2012). Revista História Hoje, ANPUH, v. 2, nº 4, p. 213-240 - 2013.

RAMPINELLI, Waldir José. A Revolução Mexicana: seu alcance regional, precursores, a luta de classes e a relação com os povos originários. Revista Espaço Acadêmico, n126, nov. 2011, p. 90-107.

SILVA, Edlene. Livros Didáticos e ensino de História: a Idade Média nos Manuais escolares do Ensino Fundamental. Revista História \& Ensino, Londrina, v. 17, nº 1, p.0731, 2011.

SILVA, Jeferson Rodrigues da. Leitores e leituras em aulas de História: professores, alunos e a inventividade sobre o livro didático. Revista História \& Ensino, Londrina, vol. 16, n.1, p.7-23, 2010.

SOARES, Jandson Bernardo. Espaço escolar e livro didático de história no Brasil: a institucionalização de um modelo a partir do Programa Nacional do Livro Didático (1994 a 2014). Dissertação. Universidade Federal do Rio Grande do Norte. Programa de pósgraduação em História, 2017.

STREICH, Ricardo Neves. A Revolução Mexicana e as esquerdas latino-americanas nos anos de 1920. REH, ano IV, vol 4, n 8, jul/dez 2017, p. 112-138.

TOSI, Marcela de Castro, Las soldaderas: mulheres na Revolução Mexicana de 1910. Revista Outras Fronteiras, Cuiabá, vol3, n1, jan./jun 2016, p.142-156. 